\title{
Revisión bibliográfica de Implantología Bucofacial del año 2008. Primera parte
}

\author{
Bibliographic review of the Oral Implantology of 2008 year. \\ First part
}

\author{
SÁNCHEZ GARCÉS MA* \\ VILCHEZ PÉREZ MA** \\ CORTELL BALLESTER I** \\ NÚÑEZ URRUTIA $S * *$ \\ SALA PÉREZ S** \\ GAY ESCODA C ***
}

\begin{abstract}
Sánchez Garcés MA, Vilchez Pérez MA, Cortell Ballester I, Núñez Urrutia S, Sala Pérez S, Gay Escoda C. Revisión bibliográfica de Implantología Bucofacial del año 2008. Primera parte. Av Periodon Implantol. 2010; 22, 2: 91-107.
\end{abstract}

\section{RESUMEN}

La actividad asistencial de los profesionales de la Odontología tiene como consecuencia una baja disponibilidad de tiempo para dedicarse a la lectura de artículos científicos. Ante la dificultad de mantener un buen nivel de información en el campo de la Implantología Bucofacial, nuestro interés es exponer de forma sintética una revisión de la literatura científica publicada en las revistas más relevantes de la especialidad durante el año 2008. El lector interesado encontrará en este artículo algunos de los diferentes temas que integran esta disciplina, expuestos por apartados (plan de tratamiento, pacientes especiales, diseño y superficies, regeneración ósea, regeneración tisular guiada, carga inmediata, pacientes irradiados, implantes extraorales).

PALABRAS CLAVE: Implantología bucofacial, plan de tratamiento, pacientes especiales, diseño de superficies, ROG, carga inmediata, pacientes especiales, radioterapia, implantes extraorales.

\section{SUIMIMARY}

The lack of the available time of professionals involved in the Odontologic field and the difficulty to maintain a good level of information about Oral Implantology, arouse the interest of these authors to expose a synthetic review of 2008 publications in the most relevant dental journals. Inside this article there are different aspects related to treatment planning, special patients, design and surfaces, immediate load, guided bone regeneration, guided tissue regeneration, radiotherapy and extraoral implants.

KEY WORDS: Oral implantology, treatment plannig, special patients, implant surface, inmediate load, GTR, radiotherapy, extraoral implants.

Fecha de recepción: 14 de mayo de 2009.

Fecha de aceptación: 25 de mayo de 2009.

Profesora asociada de Cirugía Bucal y Profesora del Máster de Cirugía Bucal e Implantología Bucofacial. Facultad de Odontología de la Universidad de Barcelona. Investigadora del Instituto IDIBELL.

** Licenciado en Odontología. Residente del Máster de Cirugía Bucal e Implantología Bucofacial. Facultad de Odontología de la Universidad de Barcelona.

*** Catedrático de Patología Quirúrgica Bucal y Maxilofacial. Director del Máster de Cirugía Bucal e Implantología Bucofacial. Facultad de Odontología de la Universidad de Barcelona. Investigador coordinador del Instituto IDIBELL. Jefe del Servicio de Cirugía Bucal, Implantología Bucofacial y Cirugía Maxilofacial del Centro Médico Teknon de Barcelona. 


\section{INTRODUCCIÓN}

Uno de los factores que hacen atractiva la Implantología Bucofacial es la constante renovación de los conceptos, ideas y técnicas que se aplican a los pacientes, ya sean fruto de la investigación básica aplicada, del desarrollo industrial de nuevos recursos terapéuticos, de la posible utilización de numerosas opciones quirúrgicas o de la aplicación de productos desarrollados desde otros campos de las Ciencias biomédicas, como podrían ser los derivados de la Ingeniería tisular. Esta virtud comporta una importante dificultad que es la de mantenerse al día, para así dar el mejor servicio posible a nuestros pacientes. Debido al gran número de artículos publicados durante el año 2008 en el área de la Implantología, es difícil disponer del tiempo suficiente para hacer una lectura crítica de los mismos. El objetivo de este trabajo es ofrecer al lector una revisión de los principales temas relacionados con la Implantología Bucofacial que se han publicado durante este año en las revistas científicas más relevantes.

\section{GENERALIDADESY PLAN DE TRATAMIENTO}

La Implantología Bucofacial ha constituido un importante avance de la Odontología en los últimos 30 años. La alta predictibilidad de las técnicas quirúrgicas empleadas y su baja incidencia de fracasos han hecho que se deba considerar la colocación de implantes dentales como primera elección en la rehabilitaciónrestauración bucodental. Asimismo, la cirugía reconstructiva de tejidos duros y blandos en pacientes afectados por tumores y traumatismos maxilares se ha visto favorecida por el desarrollo de los implantes osteointegrados (1).

En el éxito de los tratamientos implantológicos influyen diversos factores, algunos no controlables por el profesional, y otros que pueden serlo en mayor o menor medida. Respecto al paciente, puede hacerse la misma consideración, siendo la patología sistémica un factor poco controlable. La higiene bucal, la presencia de hábitos tóxicos (tabaco, alcohol y otros) y el tipo de alimentación serían factores que pueden ser modificados por el paciente. Respecto al tipo de alimentación, recientemente se ha publicado una investigación en un modelo "ex vivo", que demuestra que el consumo de sustancias a elevada temperatura favorece la lesión de los tejidos periimplantarios, comprometiendo incluso la parte más coronal del implante (2).
Entre los factores relativos al profesional que condicionan el éxito de un tratamiento, es importante incluir el conocimiento exacto de cuáles son las demandas y expectativas del paciente. Berretin y cols. (3), evaluaron la calidad de vida mediante un cuestionario, antes y después del tratamiento implantológico, en una muestra de 15 pacientes mayores de 60 años totalmente edéntulos. El tratamiento realizado en todos los pacientes fue una prótesis fija implantosoportada. Los resultados mostraron una mejor calidad de vida después de la rehabilitación bucodental mediante implantes osteointegrados.

Sin embargo, esto no debería hacernos pensar en convertir a todos los pacientes en usuarios de prótesis fija de forma obligada. Las sobredentaduras implantorretenidas son un tratamiento eficaz, tanto en casos de edentulismo total como parcial, y permiten lograr un alto grado de satisfacción disminuyendo los costes económicos que suponen las restauraciones más complejas (4).

También se han mejorado los resultados en tratamientos restauradores con un elevado compromiso estético. Las ausencias dentarias en la parte anterior del maxilar superior, ya sean de causa congénita o adquirida, se han visto ampliamente beneficiadas de la terapia con implantes y de la aparición de técnicas coadyuvantes como la regeneración tisular guiada (5-7).

A pesar de todo lo que hemos comentado, uno de los factores más importantes para poder llevar a cabo cualquier procedimiento implantológico es un conocimiento exhaustivo de la anatomía. Durante la cirugía se deben reconocer y respetar todas las estructuras óseas, nerviosas, musculares y vasculares que estén relacionadas con el territorio anatómico implicado. El nervio dentario inferior y el nervio mentoniano serán las principales estructuras nerviosas a tener en cuenta durante la colocación de implantes en la mandíbula, mientras que en el maxilar superior, los principales obstáculos anatómicos son los senos maxilares y las fosas nasales (8). No debe olvidarse que se trata de un territorio muy vascularizado, por lo tanto debe practicarse una técnica quirúrgica lo más atraumática posible para evitar complicaciones hemorrágicas. Aún así, la presencia de anomalías anatómicas como la foramina lingual puede generar complicaciones de este tipo, ya que a través de estos conductos intraóseos penetran ramas de las arterias sublinguales y submentonianas. Está bien descrita la prevalencia de estas estructuras en la línea media mandibular. Sin embargo según Kawai y cols. (9), estos conductos también pueden es- 
tar presentes a nivel canino y premolar. Los autores establecen una prevalencia en esta localización del $69,7 \%$ en total. Un $33,3 \%$ se presentará de forma unilateral y el $36,4 \%$ restante de forma bilateral.

Se han publicado diversos estudios que evalúan los diferentes métodos para determinar con exactitud la cantidad de hueso disponible en los maxilares para la colocación de implantes dentales. Sin embargo, la cantidad de hueso disponible no será el único factor a tener en cuenta, ya que el patrón de reabsorción y la calidad del hueso también van a condicionar el tratamiento implantológico a corto y largo plazo $(10,11)$.

Las pruebas radiológicas más empleadas en Implantología Bucofacial para la evaluación preoperatoria son: la radiografía periapical, la ortopantomografía y la tomografía computadorizada (TC). Existen publicadas dos guías prácticas que nos orientan sobre las pruebas radiológicas necesarias previas a la colocación de implantes dentales. Una de ellas ha sido propuesta por la European Association for Osseointegration (EAO) y la otra por la American Academy of Oral and Maxillofacial Radiology (AAOMR). Sin embargo, en una encuesta efectuada por McCrea (12), el $80 \%$ de los profesionales que se dedican a la Implantología no basan sus planes de tratamiento en ningún protocolo establecido y toman sus decisiones de forma individualizada para cada paciente. Estos resultados plantean dudas sobre la relevancia clínica y la utilidad de estas guías prácticas, aunque estamos absolutamente de acuerdo en que es necesario crear unos criterios de selección bien establecidos por parte de radiólogos e implantólogos experimentados.

La ortopantomografía es la prueba radiológica más usada en Odontología ya que permite obtener una visión general de los maxilares y las estructuras adyacentes. Su uso en Implantología también es generalizado, excepto en aquellas situaciones de compromiso óseo, donde debe ser complementada con otras radiografías. Uno de los problemas de la ortopantomografía es la magnificación y distorsión que presenta, aunque autores como Vasquez y cols. (13) han demostrado que la utilización de objetos de un diámetro predeterminado permiten la calibración de las mediciones óseas verticales de forma fiable. Para obtener mediciones óseas horizontales se recurre a la TC. Aún así, no hemos de olvidar que disponemos de técnicas menos costosas y más rápidas como es el mapeo ("mapping"). Chen y cols. (11) compararon las mediciones de la anchura ósea obtenidas con "mapping" y TC respecto a la anchura ósea real evaluada una vez levantado el colgajo en la cirugía implantológica. Observaron que el "mapping" era más consistente y se acerca más a la realidad que la TC, sobretodo en sectores anteriores del maxilar superior.

Tal y como se ha mencionado anteriormente, no solo va a ser importante la cantidad ósea, sino también su calidad. Nackaerts y cols. (14) investigaron la relación entre la pérdida de hueso alveolar a nivel mandibular y la calidad y densidad óseas evaluadas en la ortopantomografía. Obtuvieron una relación estadísticamente significativa entre la densidad ósea y la pérdida de hueso alveolar, de manera que a medida que disminuía la densidad había una mayor pérdida ósea.

Aguiar y cols. (15) compararon la eficacia de la resonancia magnética (RM) y la TC en la determinación de la cantidad ósea. Estos autores no obtuvieron diferencias entre ambas pruebas de diagnóstico por la imagen, aunque la RM tiene la ventaja de que no utiliza radiaciones ionizantes. Sin embargo hay que destacar que el estudio presenta limitaciones, ya que fue hecho en mandíbula de cadáver, eliminando muchos factores que pueden distorsionar los resultados.

Hasta ahora se han evaluado los diferentes métodos para determinar la cantidad y calidad óseas. No obstante, el implante no debe simplemente colocarse donde hay hueso disponible sino que también debe cumplir los requisitos protésicos exigidos a cada caso. En la actualidad los elementos que más se usan para determinar la posición y angulación de los implantes son las férulas quirúrgicas. Muchas veces la misma prótesis del paciente puede usarse para tal fin y en otras ocasiones puede servir para confeccionar una prótesis inmediata. Fischer y cols. (16) compararon la carga inmediata con la carga diferida de implantes colocados en el maxilar superior para la rehabilitación de arcadas completas. Observaron que la carga inmediata no compromete la viabilidad de los implantes dentales a los 5 años. Se obtienen así beneficios estéticos $y$ funcionales para el paciente.

En definitiva, el diagnóstico implantológico correcto se basa en la interpretación adecuada de las demandas del paciente, los estudios clínico, radiológico y protésico previos, un conocimiento exacto de la anatomía y la fisiología del paciente y en la utilización de todos aquellos instrumentos necesarios para la correcta colocación de los implantes. Sin tener en cuenta todos estos factores, la cirugía implantológica no se puede considerar predecible y no se conseguirían los resultados esperados. 


\section{PACIENTES ESPECIALES}

\section{Paciente periodontal}

De acuerdo con la revisión que publicó Heitz-Mayfiled (17) con motivo del $6^{\circ}$ Workshop Internacional de Periodoncia, las enfermedades que afectan a los tejidos periimplantarios pueden evolucionar a lo largo del tiempo, tal como ocurre en los diferentes tipos de enfermedad periodontal. Aunque no se ha observado una relación directa entre la periodontopatía que presenta el paciente y el fracaso del implante, la mayoría de los trabajos revisados coinciden en que la enfermedad periodontal puede estar implicada en fenómenos como la periimplantitis, la mucositis, la pérdida de hueso marginal, el sangrado gingival y el aumento de la profundidad de sondaje. Kanno y cols. (18) y Schou (19) llegan a la misma conclusión que Heitz-Mayfield (17) en este tipo de pacientes. Según todos estos autores, el seguimiento y la instauración de un correcto tratamiento periodontal reduce el número de complicaciones y aumenta el tiempo de supervivencia de los implantes.

\section{Tabaquismo}

El estudio de los efectos del tabaco sobre los tejidos periimplantarios es un tema recurrente en la literatura. La nicotina provoca vasoconstricción arteriolar, descenso del flujo sanguíneo, alteraciones del sistema inmunológico, susceptibilidad a la infección, retraso en la cicatrización de las heridas y un mayor riesgo de fracaso de los implantes dentales (20). Por el contrario estudios "in vitro" han demostrado el crecimiento de células osteoblásticas sobre la superficie de un implante en presencia de bajas concentraciones de nicotina (2l).

En la revisión llevada a cabo por Heitz-Mayfield (17) se observaron diversas complicaciones (periimplantitis, mucositis, mayor pérdida de hueso marginal periimplantario, sangrado gingival y mayor profundidad al sondaje periodontal) y una mayor pérdida de implantes en los pacientes fumadores respecto a los no fumadores. Susarla y cols. (22) también establecen una tasa de fracaso 2,6 veces superior en los pacientes fumadores respecto a los no fumadores. Aunque existen estudios como los de Sverzut y cols. (23) en los que no se encontraron diferencias estadísticamente significativas entre la pérdida temprana de implantes y el hábito tabáquico.

\section{Diabetes}

La Diabetes Mellitus (DM) es una enfermedad sistémica de origen endocrino con una elevada prevalencia en la población (5-10\%). Representa un factor de riesgo para la supervivencia de los implantes, sobre todo en los pacientes mal controlados (24).

Heitz-Mayfield (17) observa una elevada relación entre la DM y el fracaso del tratamiento implantológico. Sin embargo, otros autores no encuentran esta correlación $(25,26)$. A pesar de los resultados contradictorios que se han presentado, la DM no debe representar una contraindicación para la colocación de implantes. Se debe informar correctamente al paciente sobre las posibles complicaciones y éste debe seguir un adecuado control metabólico (17).

\section{Pacientes tratados con bifosfonatos}

En el año 2002 la Agencia Americana para el Medicamento (FDA) advirtió a las comunidades médica y odontológica del riesgo de aparición de osteoquimionecrosis $(\mathrm{OQN})$ en los pacientes tratados con bifosfonatos (BF). Este tipo de complicación suele aparecer en aquellos pacientes a los que se les administran estos fármacos por vía endovenosa. Clínicamente se caracteriza por existir una exposición de hueso necrótico, que se acompaña de dolor y mal sabor de boca (27-29).

Se han observado algunos casos de OQN asociados a la ingesta de BF orales. Para la FDA el tratamiento implantológico en estos pacientes representa una contraindicación relativa. En los pacientes de edad avanzada la asociación de tratamientos largos con corticoides y $\mathrm{BF}$ orales son una contraindicación absoluta. Por el contrario, Bell y Bell (30) no observaron ninguna complicación asociada al uso de BF orales.

En este tipo de pacientes, se aconseja realizar controles clínicos periódicos y evitar cualquier tipo de trauma quirúrgico (31). Curiosamente estudios experimentales con ratas ooforectomizadas y tratadas con $\mathrm{BF}$, se ha observado un mayor contacto entre la superficie del implante y el hueso (32-34).

\section{Osteoporosis}

La osteoporosis es una enfermedad metabólica que afecta principalmente a las mujeres postmenopáusicas. Los trabajos publicados defienden la colocación 
de implantes en estas pacientes al no existir diferencias significativas en cuanto a las tasas de éxito, que oscilan del 93,8\% al 100\% $(25,35)$. Otros autores demuestran que no existe una relación directa entre la densidad ósea periférica y la calidad y la densidad de los huesos maxilares (36). En estudios histomorfométricos se ha observado un elevado porcentaje de contacto entre la superficie del implante y el hueso de pacientes con osteoporosis $(37,38)$. A pesar de ello, Torres y cols. (39) sugieren el empleo de plasma rico en plaquetas en estos pacientes para favorecer la angiogénesis y reducir el tiempo de maduración ósea en el proceso de osteointegración.

\section{Otras osteopatías y malformaciones bucofaciales}

La rehabilitación con implantes dentales en pacientes con enfermedades óseas y con determinadas malformaciones dentomaxilofaciales ha dado a lugar a excelentes resultados estéticos y funcionales $(40,41)$.

Se han publicado algunos casos en que los implantes dentales podrían estar relacionados con el desarrollo de neoplasias benignas (granuloma periférico de células gigantes (42), tumor odontogénico queratoquístico (43) y malignas (osteosarcoma) (44). Entre las posibles causas del origen de estas lesiones se establece que los implantes podrían provocar una irritación local o que los componentes de los implantes (cromo, cobalto, zinc, selenio, o incluso el titanio) podrían tener un efecto carcinogenético sobre el hueso o los tejidos blandos $(44,45)$.

\section{Radioterapia/implantes extraorales}

La radioterapia indicada en los pacientes con cáncer de cabeza y cuello constituye un factor de riesgo importante asociado al fracaso de los implantes empleados para su posterior rehabilitación bucomaxilofacial $(46,47)$. Sin embargo, Adell y cols. (48) y Schoen y cols. (49) obtuvieron una tasa de éxito del $90 \%$ y $99 \%$ respectivamente, en pacientes tratados con radioterapia. Estos autores sugieren colocar los implantes en el momento de la resección del tumor ya que se disminuye el tiempo de espera para la rehabilitación protésica y el proceso de osteointegración aún no se ve alterado por la radiación.

La colocación de implantes extrabucales mediante la utilización de sistemas de cirugía guiada permiten una mayor precisión y un técnica quirúrgica más atraumática en el tratamiento reconstructivo facial tras resecciones quirúrgicas oncológicas (50). En los pacientes irradiados la tasa de éxito de los implantes extrabucales disminuye de manera importante, sobre todo cuando se alcanzan dosis superiores a los 50 Gy (5.000 rads) (51). La región mastoidea es la zona con mayor tasa de éxito en la supervivencia de los implantes (casi un 100\%), seguida de la región nasal y la órbita (51-53). Karakoca y cols. (52) obtuvieron una tasa de éxito de un 72,7\%. La falta de higiene en estas zonas también puede comprometer la viabilidad de los implantes. Los mejores resultados se obtienen cuando se combina el tratamiento de la radioterapia con la terapia de oxígeno hiperbárico $(51,54)$.

\section{SUPERFICIES Y DISEÑOS}

El concepto de osteointegración ha impulsado el desarrollo de nuevas directrices en el diseño y la utilización de diferentes materiales con la finalidad de mejorar la tasa de éxito de los implantes dentales intraóseos. La competencia industrial ha potenciado la investigación de nuevos conceptos como las superficies bioactivas (osteopromotoras, osteoinductoras y osteogénicas), capaces de estimular la adhesión, agregación y promoción celular. El desarrollo de las superficies bioactivas pretende mejorar las propiedades osteointegradoras de las superficies de los implantes (55-60).

Estos tipos de superficies actúan favoreciendo la agregación de componentes inorgánicos y celulares (proteínas y osteoblastos) permitiendo la osteointegración por contacto directo (OCD), lo que facilita una rápida curación ósea y una mayor estabilidad de los implantes sometidos a carga respecto a los implantes con osteointegración a distancia (OD). Finalmente, tanto la OCD como la OD seguirán el patrón normal de osificación centrípeta $(56,58,61,62)$. En la actualidad, también se ha demostrado que las superficies rugosas favorecen el fenómeno de la osteoinducción $(58,61,63-66)$, ya que son capaces de estimular la migración y adhesión celulares, acelerando la curación ósea y aumentando la superficie de contacto (SC) entre el implante y el hueso $(58,61,63-66)$ (Nosotros no estamos de acuerdo con esta terminología, ya que siendo estrictos, las superficies no influyen de forma directa en la diferenciación de las células madre hacia células osteoprogenitoras).

Gurgel y cols. (66) demostraron una mayor SC del implante rugoso tratado mediante oxidación, comparado con implantes de superficie mecanizada. Mangano y cols. (65) corroboraron el trabajo del equipo de Gurgel y cols. (66) en un estudio comparativo entre implantes mecanizados e implantes tratados mediante grabado 
ácido (GA). El estudio de Mangano y cols. (65) observó que las superficies gravadas mostraban una elevada osteoconductividad mejorando la adhesión, proliferación y diferenciación celulares además de favorecer un aumento de la angiogénesis periimplantaria.

El uso de implantes dentales con superficie rugosa favorece la aposición ósea alrededor de los implantes (61, 63-69). En la mayoría de los estudios consultados se ha evidenciado una mayor curación temprana del hueso periimplantario utilizando implantes con superficies tratadas que empleando superficies mecanizadas en pacientes con baja densidad ósea (61, 64-66, 69). Algunos autores aseguran no observar diferencias estadísticamente significativas en relación con la pérdida ósea tardía entre los dos tipos de superficies $(61,63-66,69,70)$.

Existe controversia en la elección del tipo de superficie (55-57, 60-62, 64-67, 69, 71-73). Algunos autores, abogan por la utilización de superficies cubiertas con hidroxiapatita o fosfato cálcico, confirmando un incremento de su SC. El recubrimiento de las superficies de los implantes con estas sustancias favorece el anidamiento precoz de células con poder osteogénico (57, 58). Thierer y cols. (57) observaron, en un estudio con implantes cubiertos con hidroxiapatita, un índice de éxito del $97 \%$ reportando una correcta estabilidad de los tejidos periodontales en un $99,45 \%$ de los pacientes.

Le-Guehennec y cols. (67) realizaron un estudio comparativo de diferentes tipos de superficies de implantes. Las superficies comparadas fueron de arenado de alúmina (alúmina-Ti), fosfato cálcico bifásico (BCP-Ti), fosfato octacálcico (OCP-Ti) y arenado con partículas de gran tamaño y GA (PGT-GA). El estudio reportó, a las 2 semanas, una mayor $\mathrm{SC}$ hueso-implante para las superficies con PGT-GA. Sin embargo, a las 8 semanas observaron una mayor SC para las superficies con OCP-Ti. Los autores concluyeron que los resultados obtenidos por las superficies OCP-Ti y PGT-GA no mostraban diferencias estadísticamente significativas.

En otro estudio, que comparaba implantes con diferentes diámetros y tratados mediante GA o por electrodeposición, Jung y cols. (68) no encontraron diferencias significativas entre ambas superficies tras efectuar un control clínico a los 5 años después de su inserción. Yang y cols. (64) defienden el tratamiento con doble GA en superficies de implantes, tratadas previamente mediante arenado, confirmando un aumento de la SC hueso-implante mediante estudios histomorfométricos y un aumento del torque de remoción durante la extracción de los implantes osteointegrados en tibias de conejos. Estos autores aseguran que el doble GA elimina las partículas residuales no adheridas durante el arenado, evitando el posible desplazamiento de las partículas libres durante su inserción y favoreciendo la normal aposición ósea. Estos resultados coinciden con los aportados por otros autores $(74,75)$.

La capacidad osteoconductora de la hidroxiapatita, del calcio y del colágeno están siendo aplicadas en la superficie de los implantes por su acción estimuladora celular en la interfase hueso-implante $(56-58,60,61)$.

La utilización de óxido de circonio en la fabricación de implantes dentales se encuentra en alza actualmente $(71,76)$. Los últimos trabajos publicados demuestran resultados positivos. Sin embargo, son necesarios más estudios que permitan conocer las propiedades de este nuevo material a largo plazo (71, 72, 77-79).

Las superficies tratadas con proteínas morfogenéticas óseas (BMPs) han demostrado ser las primeras superficies con propiedades osteogénicas $(80,81)$. Sin embargo, Stadlinger y cols. (56), efectuaron un estudio donde comparaban implantes recubiertos con diferentes materiales: colágeno; colágeno y condroitín sulfato; y colágeno, condroitín sulfato y BMP-4. Observaron una menor SC en los implantes tratados con colágeno, condroitín sulfato y BMP-4. Este resultado, según la hipótesis de los autores, puede estar motivado porque las BMPs redujeron la capacidad de interacción entre la matriz y los factores de crecimiento endógenos del condroitín sulfato.

Una de las características que debe cumplir toda superficie bioactiva es la estimulación de la migración y la adhesión celular. La respuesta celular se traducirá en un aumento de la SC hueso-implante y en una curación ósea más rápida que en las superficies no bioactivas $(56-60,62,82)$.

Respecto al diseño macroscópico, algunos autores defienden el uso de implantes de diámetro estrecho en pacientes con atrofia alveolar (83-85). Aunque debemos tener en cuenta el riesgo de fractura de los implantes con un diámetro $\leq 3 \mathrm{~mm}$ (86). Autores como Degidi y cols. (84) afirman no encontrar diferencias estadísticamente significativas en la supervivencia de los implantes de plataforma estrecha respecto a los de plataforma estándar, a pesar de que existe una mayor pérdida ósea inicial en los primeros cuando son sometidos a carga temprana.

También se ha observado una pérdida ósea temprana relacionada con los diferentes aditamentos protésicos 
utilizados sobre los implantes. Quaresma y cols. (87) observaron un mayor estrés sobre la cortical ósea en los implantes sometidos a carga con pilares hexagonales de conexión interna respecto a los implantes que utilizaban pilares cónicos.

La utilización de pilares con reducción de plataforma es una de las nuevas tendencias en Implantología. Schrotenboer y cols. (88), mediante un análisis de elementos finitos, demostraron una reducción del estrés sobre el hueso marginal en implantes con este tipo de pilares. Este dato contrasta con los aportados por otros autores que aseguran que la utilización de los pilares con reducción de plataforma favorece la pérdida ósea a nivel cervical, sobre todo, en aquellos implantes enterrados $1 \mathrm{~mm}$ respecto al nivel del hueso crestal (83).

\section{IMPLANTES INMEDIATOS}

Se define como implante inmediato a aquel implante cuya colocación se lleva a cabo en el alveolo inmediatamente después de la exodoncia (89).

La colocación de implantes inmediatos está indicada en casos de caries extensas subcrestales, fracturas radiculares, fracasos endodóncicos y coronas no restaurables (90).

Las ventajas descritas son: la reducción de la duración del tratamiento, el mantenimiento del perfil de los tejidos blandos, la prevención de la pérdida ósea tanto vertical como horizontal y la disminución del número de intervenciones quirúrgicas. Además, la colocación de un implante inmediato reduce la necesidad de fresado óseo por lo que disminuyen el trauma quirúrgico y el riesgo de necrosis ósea $(90,91)$.

La desventaja principal es el coste adicional asociado, ya que normalmente es necesario el uso de materiales de regeneración ósea. Así mismo, el procedimiento es técnicamente mucho más exigente que la técnica diferida tradicional (91).

La preparación del lecho presenta ciertas peculiaridades que la diferencian de la técnica tradicional. En primer lugar, el implante debe colocarse anclado a la cortical lingual o palatina con una distancia mínima de 2 milímetros entre el implante y la cortical vestibular. Además, debe colocarse por debajo del nivel crestal para compensar la reabsorción esperada. La plataforma del implante debe quedar de 2 a 3 milímetros apical a la línea amelocementaria del diente adyacente (92).
En los dientes multirradiculares, la inserción de implantes inmediatos conlleva la dificultad añadida de colocar el implante en la posición ideal para llevar a cabo la restauración protésica. En este sentido, Fugazzotto (93) presenta un protocolo de tratamiento para la extracción de molares superiores y la colocación inmediata de implantes utilizando el septo interradicular. Después de la extracción de los molares llevando a cabo la odontosección de cada una de las raíces para preservar el hueso interradicular, el autor divide los casos en 4 grupos:

- Grupo 1: Altura de hueso alveolar suficiente y tabique interradicular ancho. Con una fresa guía de 2,2 $\mathrm{mm}$ se prepara el lecho hasta la profundidad final y posteriormente, con osteótomos cónicos de diámetros crecientes se acaba de preparar el lecho del implante. Se coloca el implante y se rellena el defecto residual con un injerto de material particulado, excepto en el caso de que el espacio entre el implante y el hueso no exceda de $3 \mathrm{~mm}$. Para finalizar, se recubre con una membrana reabsorbible y se cierra por primera intención.

- Grupo 2: Altura de hueso alveolar suficiente y septo interradicular estrecho. En primer lugar, con una fresa de 2,2 $\mathrm{mm}$ se marca la parte más crestal del hueso interradicular. En este caso se llega a la profundidad final con un osteótomo cónico de 2,2 mm de ancho. Posteriormente, con osteótomos de diámetros crecientes se acaba de preparar el lecho del implante. Para finalizar, se utilizan materiales de regeneración ósea y se cierra el colgajo por primera intención.

- Grupo 3: Altura de hueso alveolar insuficiente y septo interradicular ancho. En este caso, con una fresa de 2,2 $\mathrm{mm}$ se prepara la ostectomía hasta 1 $\mathrm{mm}$ del suelo del seno maxilar y con un osteótomo plano se empuja el hueso para llevar a cabo la elevación de la membrana sinusal. Con osteótomos de diámetros crecientes se acaba de preparar el lecho en anchura y se coloca el implante.

- Grupo 4: Altura de hueso alveolar insuficiente y septo interradicular estrecho. Se utiliza directamente un osteótomo de $2,2 \mathrm{~mm}$ hasta la profundidad deseada para aumentar la altura ósea, nunca excediendo el milímetro de distancia hasta el suelo del seno maxilar. Se ensancha el lecho con osteótomos y se coloca el implante. Como en los grupos anteriores se utilizan materiales de regeneración ósea y se cierra el colgajo por primera intención.

Siguiendo este protocolo, el autor presenta una serie de 391 implantes colocados en 386 pacientes inmediatamen- 
te después de la extracción de molares superiores. Obtiene una supervivencia acumulada del $99,5 \%$, con un tiempo de seguimiento máximo de los implantes cargados de 75 meses y una media de 40,3 meses (93).

El mismo autor (94) presenta una serie de 341 implantes colocados inmediatamente después de la extracción de molares mandibulares, encontrando una supervivencia acumulada del $99,1 \%$ con un tiempo de seguimiento máximo de los implantes cargados de 6 años y una media de 30,8 meses.

La posibilidad de utilizar técnicas combinadas implante inmediato-carga inmediata ha sido propuesta recientemente con buenos resultados clínicos pero sin suficientes datos histológicos respecto a la respuesta del hueso periimplantario. Guida y cols. (95) presentan el caso de una paciente de 63 años de edad, a la que se le colocaron implantes en las zonas edéntulas del maxilar superior para posteriormente llevar a cabo la rehabilitación protésica. Además, la paciente consintió que en la misma intervención quirúrgica se le extrajeran los terceros molares superiores y se le colocaran 2 implantes inmediatos. Uno de ellos con carga inmediata. Después de 6 meses se llevó a cabo un control clínico y radiológico de los implantes y fueron extraídos con el hueso periimplantario para analizarlos histológicamente. Según los autores, los 2 implantes estaban osteointegrados y clínicamente estables. No obstante, el implante con carga inmediata estaba rodeado de un hueso más maduro y bien organizado, presentando áreas de remodelación ósea. Sin embargo, el implante no cargado estaba rodeado de hueso poco trabeculado.

Respecto a los implantes en la zona anterior, Degidi y cols. (96) han analizado los resultados tras la colocación de 152 implantes inmediatos con carga inmediata en 49 pacientes. Para ello, estudian las diferencias en los niveles del hueso y del tejido blando periimplantarios en función de la distancia entre los implantes. Las conclusiones de su estudio son que para garantizar unos buenos resultados estéticos, el punto de contacto entre las 2 coronas protésicas debe estar localizado de 3 a $4 \mathrm{~mm}$ de la cresta ósea y nunca a más de $6 \mathrm{~mm}$. Por otro lado, la distancia entre los implantes debe ser mayor de $2 \mathrm{~mm}$ y menor de $4 \mathrm{~mm}$.

La colocación temprana del implante es una alternativa interesante a los implantes inmediatos. En este caso, la inserción se difiere de 4 a 8 semanas después de la exodoncia esperando a la completa curación del tejido blando que permitirá el cierre por primera intención (92).

\section{CARGA INMEDIATA}

Tradicionalmente se ha sugerido que después de la colocación de implantes es necesario un tiempo de curación de entre 3 y 6 meses para asegurar una adecuada osteointegración (97). Sin embargo, hoy en día, numerosos autores abogan por la carga inmediata de los implantes (97-101).

Las ventajas de la carga inmediata son claras. Permite unos tiempos de tratamiento más cortos y una restauración inmediata de la estética y de la función. Esto proporciona una mayor satisfacción al paciente y evita la dificultad de llevar prótesis removibles durante el tiempo de curación (101).

Para la mayoría de los autores (98-100, 102-106) la carga inmediata no afecta negativamente a la estabilidad del implante ni al nivel óseo periimplantario y lo consideran una alternativa fiable y predecible a la terapéutica convencional.

Una buena estabilidad primaria del implante es fundamental para obtener resultados predecibles con carga inmediata. Los factores que determinan dicha estabilidad son la calidad y el volumen óseos, la técnica quirúrgica, el diseño y la superficie del implante $(105,106)$.

Collaert y De Bruyn (106) estudian los resultados de 195 implantes colocados con carga inmediata para la rehabilitación de maxilares edéntulos, con un periodo de seguimiento de 3 años. Obtienen un porcentaje de supervivencia del $100 \%$ tanto de los implantes como de las prótesis con una media de pérdida ósea periimplantaria a los 3 años de 0,72 mm. Según los autores, se observó una mayor pérdida de altura ósea en los pacientes fumadores y concluyen que esta técnica tiene un buen pronóstico a largo plazo.

Del mismo modo, Fischer y cols. (99) en un estudio clínico randomizado y controlado, evalúan las diferencias, en cuanto a resultados clínicos, entre la colocación de implantes con carga temprana para la rehabilitación de maxilares edéntulos y la colocación de implantes con carga diferida, con un periodo de seguimiento de 5 años. Los autores no encuentran diferencias importantes entre las 2 técnicas, por lo que concluyen que la carga temprana representa una técnica viable para este tipo de tratamientos.

Sin embargo, Kim y cols. (101) afirman que los implantes con carga inmediata presentan una menor osteointegración y una menor altura del hueso periimplantario después de 2 meses y medio de carga. Además, 
Susarla y cols. (97) encuentran una supervivencia al año de los implantes con carga inmediata del 90,3\%. Para los implantes con carga diferida encuentran una supervivencia del $95,5 \%$. Con estos resultados, los autores afirman que los implantes con carga inmediata tienen 2,7 veces más posibilidades de fracasar que los implantes cargados de manera diferida y concluyen que la carga inmediata es, junto al tabaco, los implantes cortos y los implantes colocados en el maxilar superior, un factor de riesgo para el éxito del tratamiento.

\section{CIRUGÍA GUIADA Y CIRUGÍA MÍNIMAIMENTE INVASIVA}

En los últimos años se han desarrollado diferentes técnicas de cirugía mínimamente invasiva que pueden proporcionar función, estética y confort a los pacientes tratados con implantes osteointegrados. La mayoría de autores (107-110) afirman que la cirugía sin colgajo es un método que disminuye el dolor, minimiza el sangrado y el disconfort postoperatorios y reduce el tiempo de la intervención quirúrgica y de curación. Además, estas técnicas preservan los tejidos blandos alrededor de los implantes, como las papilas interdentarias y los márgenes gingivales.

No obstante, las intervenciones quirúrgicas sin colgajo se consideran procedimientos "ciegos" por la dificultad para evaluar el hueso alveolar y controlar la angulación de los implantes, lo que aumenta el riesgo de fenestraciones e incluso de lesionar los dientes adyacentes (108).

Los criterios a seguir para la colocación de implantes con cirugía mínimamente invasiva son: una anchura de hueso alveolar mínima de $5 \mathrm{~mm}$ y una cantidad de encía de al menos $4 \mathrm{~mm}$ desde el margen gingival a la unión mucogingival (109).

En la literatura revisada encontramos varios artículos en los que se analiza el éxito de las técnicas de cirugía implantológica mínimamente invasiva. Choi y cols. (110) en un estudio experimental en perros, observaron que los implantes colocados sin colgajo presentaban una peor osteointegración y una menor altura de hueso periimplantario que los implantes colocados mediante la preparación de un minicolgajo.

El mismo grupo de investigadores (111) comparan la técnica quirúrgica de levantamiento de un minicolgajo con la técnica habitual. Se analizan un total de $286 \mathrm{im}-$ plantes colocados en 129 pacientes. Los autores observan una menor pérdida ósea a los 3 meses en el grupo de estudio, por lo que concluyen que la utilización de minicolgajos aumenta el éxito del tratamiento.

En cuanto a técnicas combinadas de cirugía sin colgajo junto a carga inmediata o temprana, Merli y cols. (112) nos presentan los resultados preliminares de un ensayo clínico randomizado y controlado. Se colocaron un total de 24 implantes en 20 pacientes. No se registró ningún fracaso de los implantes en ninguno de los 2 grupos, siendo el tiempo de seguimiento de los pacientes de 1 año. Con estos resultados, los autores concluyen que el uso de técnicas quirúrgicas sin colgajo para colocar implantes osteointegrados con carga inmediata o temprana es una buena opción de tratamiento, aunque los pacientes deben ser cuidadosamente seleccionados.

Por otro lado, la cirugía guiada por computadora representa un gran avance en el campo de la Implantología Bucofacial. El uso de estos métodos técnicamente sofisticados permite evaluar de forma precisa, usando técnicas radiológicas en 3 dimensiones, las limitaciones anatómicas y la cantidad de hueso disponible para la colocación de implantes. Basándonos en esta nueva tecnología no solamente es posible determinar prequirúrgicamente la mejor posición de los implantes, sino que se puede valorar dicha posición teniendo en cuenta la demanda estética del paciente (107, 108, 113-117).

No obstante, la cirugía guiada sin colgajo presenta ciertas desventajas que deben tenerse en cuenta. En primer lugar la complejidad del sistema y el coste económico total de los instrumentos necesarios, incluyendo el "software" del programa y las guías quirúrgicas y, en segundo lugar, el aumento de las posibilidades de provocar una necrosis ósea durante el fresado, ya que se reduce el acceso para una correcta irrigación externa $(107,108)$.

Existen diferentes sistemas de cirugía implantológica guiada por la imagen que son utilizados para la colocación de implantes en la cavidad bucal o en otras áreas craneofaciales, lo que ha llevado a diferentes autores a comparar algunos de estos sistemas. De este modo, Ruppin y cols. (113) llevan a cabo un estudio en el que evalúan la fiabilidad de 3 programas diferentes para la colocación de implantes mediante cirugía guiada por computadora. Se colocan 120 implantes en 20 mandíbulas de cadáveres humanos. En el primer grupo

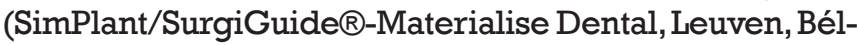
gica) los errores totales entre la posición planificada y la posición conseguida de los implantes fueron de $1,5 \pm 0,8$ $\mathrm{mm}$ (para el punto de inicio de fresado); de 0,6 $\pm 0,4 \mathrm{~mm}$ (para la profundidad de inserción); y de $7,9^{\circ} \pm 5^{\circ}$ (para la desviación axial). En el segundo grupo (RoboDent 
LapDoc Accedo®-RoboDent, Munich, Alemania) los errores totales entre la posición planificada y la posición conseguida de los implantes fueron de $1 \pm 0,5 \mathrm{~mm}$ (para el punto de inicio de fresado); de $0,6 \pm 0,3 \mathrm{~mm}$ (para la profundidad de inserción); y de $8,1^{\circ} \pm 4,6^{\circ}$ (para la desviación axial). En el tercer grupo (Artma Virtual Patient $₫$ Medlibre, Munich, Alemania) los errores totales entre la posición planificada y la posición conseguida de los implantes fueron de $1,2 \pm 0,6 \mathrm{~mm}$ (para el punto de inicio de fresado); de 0,8 $\pm 0,7 \mathrm{~mm}$ (para la profundidad de inserción); y de $8,1^{\circ} \pm 4,9^{\circ}$ (para la desviación axial). Con estos resultados, los investigadores no encontraron diferencias estadísticamente significativas entre los sistemas estudiados y concluyen que se obtuvo una buena posición de los implantes en los 3 grupos.

\section{REGENERACIÓN ÓSEA/ REGENERACIÓN ÓSEA GUIADA (ROG)}

Existen múltiples materiales usados como sustitutos óseos para corregir un defecto. Se considera que el hueso autólogo es el material de injerto ideal puesto que posee propiedades osteogénicas, osteoconductoras y osteoinductoras. No obstante, con el fin de evitar procedimientos quirúrgicos complementarios que incluyen el abordaje de zonas donantes alejadas y para disminuir la morbilidad, se ha incrementado la utilización de materiales de injerto alternativos y se potencia el interés por desarrollar nuevos biomateriales.

Numerosos autores recomiendan prevenir la reabsorción ósea mediante la preservación de la morfología alveolar con materiales de relleno desde el momento de la exodoncia, con el fin de reducir o eliminar la necesidad de futuros injertos en el reborde alveolar, además de contribuir al éxito estético y funcional de la colocación de implantes (118-122). Es posible preservar alrededor de un $85 \%$ de las dimensiones iniciales del reborde alveolar al rellenar el alveolo con xenoinjerto y membrana reabsorbible de colágeno (119).

La utilización de hueso porcino en combinación con membrana de colágeno en alveolos postextracción parece limitar la reabsorción del hueso alveolar en comparación con los casos en que no se practica ninguna técnica de regeneración ósea (RO) tras la exodoncia (121). Sin embargo, Fickl y cols. (118) concluyen en su trabajo que el relleno de los alveolos con biomateriales no logra detener el proceso de reabsorción, aunque puede limitar la pérdida de volumen en sentido horizontal. También se sugiere sobre este mismo tema, que el relleno del alveolo con Bio-Oss
Collagen $®$ (Geistlich Biomaterials, Wolhusen, Suiza) junto a un injerto gingival libre, parece actuar como un buen sistema mantenedor de espacio que a su vez permite la prevención del colapso de los tejidos blandos.

Pieri y cols. (123) en un estudio prospectivo que consistió en hacer un aumento del reborde alveolar con una membrana reforzada de titanio y una combinación de hueso autólogo y hueso bovino mineral (Bio-Oss $₫$ (Geistlich Biomaterials, Wolhusen, Suiza) en una proporción 70:30, consiguieron a los 8 ó 9 meses insertar correctamente los implantes. Obtuvieron una supervivencia del $100 \%$ y un éxito del $93,1 \%$ a los 2 años de seguimiento. Por otro lado, con este mismo material de injerto, en un ensayo clínico randomizado se evaluó la influencia de 3 técnicas de aumento del proceso alveolar: injerto de hueso autólogo de mentón con o sin membrana de colágeno [Bio-Gide® (Geistlich Biomaterials, Wolhusen, Suiza)] y el tercer grupo con Bio-Oss ${ }^{\circledR}$ y con membrana de colágeno Bio-Gide ${ }^{\circledR}$. Valoraron las características clínicas y radiológicas de los tejidos duros y de los tejidos blandos alrededor de los implantes colocados en la zona regenerada (región anterior del maxilar superior) y en los dientes adyacentes. En la evaluación realizada al año de estar cargados los implantes, se observó una correcta estabilidad de los tejidos periimplantarios en los tres grupos de tratamiento. Los márgenes óseos y gingivales no se vieron afectados en ninguna de las 3 técnicas de aumento óseo. Tampoco se encontraron diferencias significativas en cuanto a la supervivencia de los implantes (124).

Otros autores colocaron implantes de titanio de superficie arenada y grabada con ácido en defectos de 4 paredes en tibias de conejos, previamente rellenados con Bio-Oss ${ }^{\circledR}$ (Geistlich Biomaterials, Wolhusen, Suiza), Ostim ${ }^{\circledR}-P a s t e$ (Heraeus Kulzer, Hanau, Alemania), PerioGlas ${ }^{\circledR}$ (Novabone Products; LLC, Alachua, FL, EE.UU.) o ningún material. La colocación de los mencionados materiales de injerto no aportaron ninguna ventaja en la osteointegración de los implantes en este tipo de defectos según los resultados obtenidos (125).

Se ha observado in vitro que los detritus óseos resultantes del fresado en la colocación de implantes han mostrado tener potencial osteogénico (126), aunque tiene un riesgo de contaminación elevado. Tezulas y Dilek (127) llevaron a cabo una revisión de la descontaminación de los injertos de hueso autólogo obtenidos de la ostectomía de los lechos implantarios y recomiendan la utilización de protocolos de aspiración estrictos, los enjuagues de clorhexidina preoperatorios y la profilaxis antibiótica como precauciones im- 
portantes a considerar cuando se implantan partículas de hueso recolectadas de la cavidad bucal. No obstante, cualquiera de estos procedimientos únicamente reduce el riesgo de contaminación y son necesarios más estudios para determinar qué agentes antimicrobianos, en qué concentraciones y tiempos de contacto son óptimos para descontaminar las partículas óseas preservando su potencial osteogénico.

El Nanobone ${ }^{\circledR}$ (Artoss GmbH, Rostock, Alemania) es un compuesto de hidroxiapatita no sinterizada en una estructura de $\mathrm{SiO}_{2}$, con una porosidad particularmente alta. Se tomaron biopsias de zonas maxilares en humanos injertados con Nanobone $₫$ para la colocación posterior de implantes. Los autores de este trabajo postulan que se trata de un material que posee propiedades osteoconductivas y biomiméticas y que se integra en el recambio óseo fisiológico del hospedador en una fase muy temprana (128). Se ha descrito la hidroxiapatita como un material útil que permite la preservación a largo plazo del volumen en zonas regeneradas, aunque Mardas y cols. (129) no encuentran diferencias estadísticamente significativas cuando se le añade un péptido sintético útil para la unión celular (PepGen ${ }^{\mathrm{TM}}$ (Dentsply, Cera Med Dental, Lakewood, EE.UU.).

Puros Allograft $\circledast$ y Navigraft $\circledast$ (Tutogen Medical, Neunkirchen, Alemania) son dos materiales sustitutos óseos derivados de la esponjosa humana y la bovina respectivamente. Tudor y cols. (130) rellenaron defectos óseos en cerdos utilizando uno de estos dos materiales o bien hueso autólogo. En todos los casos se obtuvieron buenos resultados en la RO, aunque se observaron mayores niveles de mineralización ósea en los casos en que se utilizó hueso autólogo. Por otro lado, evaluando la reparación de defectos óseos en cráneos de rata con hueso bovino desmineralizado en comparación con hueso autólogo, De Oliveira y cols. (131) encontraron que el hueso desmineralizado bovino no logró reparar completamente los defectos, con una menor neoformación ósea que en el grupo tratado con hueso autólogo.

Una de las dificultades que presentan los diferentes materiales que se suministran en forma de partículas es su manipulación y su cohesión. Añadir poliol (carbohidrato) al hueso desmineralizado liofilizado (DFDB) produce una RO similar en comparación con el DFDB solo y a su vez mejora el manejo y la estabilidad del injerto (132).

Para la reparación de defectos óseos, la ingeniería tisular nos permite combinar células con capacidad osteogénica con un material osteoconductor apropiado. Jafarian y cols. (133) utilizaron células madre mesenquimales derivadas de la médula ósea en combinación con un compuesto de hidroxiapatita y ß-fosfato tricálcico (Kasios $₫$ (Kasios, Lanauguet, Francia), o bien con hueso mineral bovino Bio-Oss $₫$ en defectos alveolares completos en perros. Obtuvieron mejores resultados, en cuanto a la cantidad de hueso regenerado, cuando utilizaron un sustituto óseo sintético bifásico como el Kasios $®$.

La proteína ósea morfogenética humana recombinada-2 (rhBMP-2) es otro de los materiales que ha demostrado mejorar la RO y la formación de tejido mineralizado en perros $(134,135)$. A diferencia del rhBMP-2, el aloinjerto de hueso desmineralizado liofilizado (DFDBA) y la matriz derivada del esmalte poseen una capacidad limitada de inducir la formación ósea en defectos óseos amplios en cráneos de rata, por lo que puede que no sean efectivos como terapia en la regeneración de defectos óseos de tamaño crítico (136).

Una propuesta reciente defiende que las estatinas estimulan la expresión de la BMP-2 y conducen a la formación ósea. Moriyama y cols. (137) demostraron que la aplicación local de fluvastatina alrededor de implantes de titanio colocados en tibias de rata incrementaba la formación ósea. El alginato de propilenglicol, utilizado como trasportador, permite la liberación gradual y prolongada de este fármaco.

Las membranas de colágeno entrecruzado por glicosilación para ROG y regeneración tisular guiada se usan extensamente con eficacia y seguridad probadas. El análisis histológico de las muestras de tejido tomadas de 5 de los 7 pacientes del estudio de Zubery y cols. (138) mostró la osificación del colágeno entrecruzado glicosilado de las membranas, además de mejorar la densidad del hueso adyacente. Un estudio de Tal y cols. (139) evaluó la biodegradación de estas mismas membranas de colágeno entrecruzadas y no entrecruzadas al exponerse en la cavidad bucal en gatos y no se encontraron diferencias estadísticamente significativas respecto a su eficacia. Las membranas microporosas de ácido poliláctico utilizadas para ROG parecen favorecer la actividad de la neoformación ósea, de manera que pueden ser utilizadas como alternativa al injerto de hueso autólogo, aunque en el caso en que éstas se coloquen recubriendo un injerto óseo, puede observarse una mayor regeneración de los defectos en comparación con los que no se cubren (140).

\section{AGRADECIMIENTOS}

Este estudio ha sido realizado por el grupo de investigación consolidado "Patología y Terapéutica Odontológica y Maxilofacial" del Instituto IDIBELL, con el so- 
porte económico del convenio docente-asistencial de Cirugía Bucal entre la Universidad de Barcelona, el Consorci Sanitari Integral y el Servei Català de la Salut de la Generalitat de Catalunya.

\section{BIBLIOGRAFÍA}

1. Assael LA. Dental implant education and practice in oral and maxillofacial surgery: 25 years of progress. J Oral Maxillofac Surg 2008;66:611-2.

2. Feuerstein O, Zeichner K, Imbari C, Ormianer Z, Samet $\mathrm{N}$, Weiss EI. Temperature changes in dental implants following exposure to hot substances in an ex vivo model. Clin Oral Implants Res 2008;19:629-33.

3. Berretin GF, Nary Filho H, Padovani CR, Machado WM. A longitudinal study of quality of life of elderly with mandibular implant-supported fixed prostheses. Clin Oral Implants Res 2008;19:704-8.

4. Grossmann Y, Levin L, Sadan A. A retrospective case series of implants used to restore partially edentulous patients with implant-supported removable partial dentures: 31-month mean follow-up results. Quintessence Int 2008;39:665-71.

5. Barreto M, Francischone CE, Nary Filho H. Two prosthetic crowns supported by a single implant: An esthetic alternative for restoring the anterior maxilla. Quintessence Int 2008;39:717-25.

6. Winkler S, Boberick KG, Braid S, Wood R, Cari MJ. Implant replacement of congenitally missing lateral incisors: A case report. J Oral Implantol 2008;34:1 15-8.

7. Strong SM. Replacement of congenitally missing lateral incisors with implant crowns. Gen Dent 2008;56:516-9.

8. Greenstein G, Cavallaro J, Tarnow D. Practical application of anatomy for the dental implant surgeon. J Periodontol 2008;79:1833-46.

9. Kawai T, Asaumi I, Sato I, Yosue T. Lingual foramina in the canine/premolar region of the mandible: CBCT observations. Oral Surg Oral Med Oral Pathol Oral Radiol Endod 2008; 105:e53.

10. De Oliveira RC, Leles CR, Normanha LM, Lindh C, Ribeiro-Rotta RF. Assessments of trabecular bone density at implant sites on CT images. Oral Surg Oral Med Oral Pathol Oral Radiol Endod 2008;105:231-8.

11. Chen LC, Lundgren T, Hallstrom H, Cherel F. Comparison of different methods of assessing alveolar ridge dimensions prior to dental implant placement. J Periodontol 2008;79: 401-5.

12. McCrea SJ. Pre-operative radiographs for dental implants - are selection criteria being followed? Br Dent 2008;204:675-82.

13. Vasquez L, Gaydarov N, Al-Din YN, Nedir R, Bischof M, Belser UC, et al. Stability of vertical height measurements on digital panoramic radiographs using posterior mandibular implants as reference objects. Oral Surg Oral Med Oral Pathol Oral Radiol Endod 2008;105:e61.

14. Nackaerts O, Gijbels F, Sanna AM, Jacobs R. Is there a relation between local bone quality as assessed on panoramic radiographs and alveolar bone level? Clin Oral Investig 2008;12:31-5.

15. Aguiar MF, Ques AP, Carvalho AC, Cavalcanti MG. Accuracy of magnetic resonance imaging compared with computed tomography for implant planning. Clin Oral Implants Res 2008;19:362-5.

16. Fischer K, Stenberg T, Hedin M, Sennerby L. Five-year results from a randomized, controlled trial on early and delayed loading of implants supporting full-arch prosthesis in the edentulous maxilla. Clin Oral Implants Res 2008;19:433-41.

17. Heitz-Mayfield LJ. Peri-implant diseases: Diagnosis and risk indicators. J Clin Periodontol 2008;35:292-304.

18. Kanno T, Nakamura K, Hayashi E, Kimura K, Hirooka H, Kimura K. What prosthodontic therapy should we select for periodontally compromised patients? Part 1: Review of the literature focusing on implant therapy for periodontally compromised patients. Nihon Hotetsu Shika Gakkai Zasshi 2008;52:135-42.

19. Schou S. Implant treatment in periodontitis-susceptible patients: A systematic review. J Oral Rehabil 2008;35:922.

20. Balaji SM. Tobacco smoking and surgical healing of oral tissues: A review. Indian J Dent Res 2008;19:344-8.

21. Pereira ML, Carvalho JC, Peres F, Gutierres M, Fernandes $\mathrm{MH}$. Behaviour of human osteoblastic cells cultured on plasma-sprayed titanium implants in the presence of nicotine. Clin Oral Implants Res 2008; 19:582-9.

22. Susarla SM, Chuang SK, Dodson TB. Delayed versus immediate loading of implants: Survival analysis and risk factors for dental implant failure. J Oral Maxillofac Surg 2008;66:251-5.

23. Sverzut AT, Stabile GA, de Moraes M, Mazzonetto R, Moreira RW. The influence of tobacco on early dental implant failure. J Oral Maxillofac Surg 2008;66:1004-9.

24. Fiorellini J NM. Dental implant considerations in the diabetic patient. Periodontol 2000 2008;23:73-7.

25. Alsaadi G, Quirynen M, Michiles K, Teughels W, Koek A, van Steenberghe D. Impact of local and systemic factors on the incidence of failures up to abutment connection with modified surface oral implants. J Clin Periodontol 2008;35:51-7.

26. Tawil G, Younan R, Azar P, Sleilati G. Conventional and advanced implant treatment in the type II diabetic patient: Surgical protocol and long-term clinical results. Int J Oral Maxillofac Implants 2008;23:744-52. 
27. Serra MP, Llorca CS, Donat FJ. Oral implants in patients receiving bisphosphonates: $A$ review and update. Med Oral Patol Oral Cir Bucal 2008;13:E755-60.

28. Ferrari S, Bianchi B, Savi A, Poli T, Multinu A, Balestreri $A$, et al. Fibula free flap with endosseous implants for reconstructing a resected mandible in bisphosphonate osteonecrosis. J Oral Maxillofac Surg 2008;66:999-1003.

29. Marx RE. Pamidronate (Aredia) and zoledronate (Zometa) induced avascular necrosis of the jaws: A growing epidemic. J Oral Maxillofac Surg 2003;61:115.

30. Bell BM, Bell RE. Oral bisphosphonates and dental implants: A retrospective study. J Oral Maxillofac Surg 2008;66:1022-4.

31. Dodson TB, Chuang SK. Frequency estimates of BRON. Is it really zero? J Oral Maxillofac Surg 2008;66: 1558.

32. Alendronate enhance implant osseointegration: Study finds. J Am Dent Assoc 2008;139:679-80.

33. Viera Negron YE, Ruan WH, Winger JN, Hou X, Sharawy MM, Borke JL. Effect of ovariectomy and alendronate on implant osseointegration in rat maxillary bone. J Oral Implantol 2008;34:76-82.

34. Giro G, Goncalves D, Sakakura CE, Pereira RM, Marcantonio Junior E, Orrico SR. Influence of estrogen deficiency and its treatment with alendronate and estrogen on bone density around osseointegrated implants: Radiographic study in female rats. Oral Surg Oral Med Oral Pathol Oral Radiol Endod 2008;105: 162-7.

35. Holahan CM, Koka S, Kennel KA, Weaver AL, Assad DA, Regennitter FJ, et al. Effect of osteoporotic status on the survival of titanium dental implants. Int J Oral Maxillofac Implants 2008;23:905-10.

36. Slagter KW, Raghoebar GM,Vissink A. Osteoporosis and edentulous jaws. Int J Prosthodont 2008;21:19-26.

37. De Melo L, Piattelli A, Lezzi G, d'Avila S, Zenobio EG, Shibli JA. Human histologic evaluation of a six-year-old threaded implant retrieved from a subject with osteoporosis. J Contemp Dent Pract 2008;9:99-105.

38. Shibli JA, Aguiar KC, Melo L, d'Avila S, Zenobio EG, Faveri M, et al. Histological comparison between implants retrieved from patients with and without osteoporosis. Int J Oral Maxillofac Surg 2008;37:321-7.

39. Torres J, Tamimi F, Garcia I, Cebrian JL, Lopez-Cabarcos E, Lopez A. Management of atrophic maxilla in severe osteoporosis treated with bisphosphonates: A case report. Oral Surg Oral Med Oral Pathol Oral Radiol Endod 2008;106:668-72.

40. Takahashi T, Inai T, Kochi S, Fukuda M, Yamaguchi T, Matsui K, et al. Long-term follow-up of dental implants placed in a grafted alveolar cleft: Evaluation of alveolar bone height. Oral Surg Oral Med Oral Pathol Oral Radiol Endod 2008;105:297-302.
41. Bergendal B, Ekman A, Nilsson P. Implant failure in young children with ectodermal dysplasia: A retrospective evaluation of use and outcome of dental implant treatment in children in Sweden. Int J Oral Maxillofac Implants 2008; 23:520-4.

42. Cloutier M, Charles M, Carmichael RP, Sandor GK. An analysis of peripheral giant cell granuloma associated with dental implant treatment. Oral Surg Oral Med Oral Pathol Oral Radiol Endod 2007;103:618-22.

43. Tolstu L, Treasure T. Surgical treatment algorithm for odontogenic keratocyst: Combined treatment of odontogenic keratocyst and mandibular defect with marsupialization, enucleation, iliac crest bone graft, and dental implants. J Oral Maxillofac Surg 2008;66:1025-36.

44. McGuff HS, Heim-Hall J, Holsinger FC, Jones AA, O’Dell DS, Hafemeister AC. Maxillary osteosarcoma associated with a dental implant: Report of a case and review of the literature regarding implant-related sarcomas. J Am Dent Assoc 2008;139:1052-9.

45. Ciocca L, Corinaldesi G, Chetti C, Scotti R. Gingival hyperplasia around implants in the maxilla and jaw reconstructed by fibula free flap. Int J Oral Maxillofac Surg 2008;37:478-80.

46. Verdonck HW, Meijer GJ, Laurin T, Nieman FH, Stoll C, Riediger $\mathrm{D}$, et al. Implant stability during osseointegration in irradiated and non-irradiated minipig alveolar bone: An experimental study. Clin Oral Implants Res 2008; 19:201-6.

47. Alsaadi G, Quirynen M, Koek A, van Steenberghe D. Impact of local and systemic factors on the incidence of late oral implant loss. Clin Oral Implants Res 2008; 19:670-6.

48. Adell R, Svensson B, Bagenholm T. Dental rehabilitation in 101 primarily reconstructed jaws after segmental resections-possibilities and problems. An 18-year study. J Craniomaxillofac Surg 2008;36:395-402.

49. Schoen PJ, Raghoebar GM, Bouma J, Reintsema H, Burlage FR, Roodenburg JL, et al. Prosthodontic rehabilitation of oral function in head-neck cancer patients with dental implants placed simultaneously during ablative tumour surgery: An assessment of treatment outcomes and quality of life. Int J Oral Maxillofac Surg 2008;37:8-16.

50. Girod SC, Rohlfing T, Maurer CR. Image-guided surgical navigation in implant-based auricular reconstruction. J Oral Maxillofac Surg 2008;66:1302-6.

51. Leonardi A, Buonaccorsi S, Pellacchia V, Moricca LM, Indrizzi E, Fini G. Maxillofacial prosthetic rehabilitation using extraoral implants.J Craniofac Surg 2008; 19:398-405.

52. Karakoca S, Aydin C,Yilmaz H, Bal BT. Survival rates and periimplant soft tissue evaluation of extraoral implants 
over a mean follow-up period of three years. J Prosthet Dent 2008;100:458-64.

53. Gentile P, Bottini DJ, Gravante G, Nicoli F, Caruso R, CervelliV.The use of bone-anchored implants for absent ear. J Craniofac Surg 2008; 19:744-7.

54. Wright RF, Zemnick C, Wazen JJ, Asher E. Osseointegrated implants and auricular defects: A case series study. J Prosthodont 2008;17:468-75.

55. Ogawa T, Saruwatari L, Takeuchi K, Aita H, Ohno N. Ti nano-nodular structuring for bone integration and regeneration. J Dent Res 2008;87:751-6.

56. Stadlinger B, Pilling E, Huhle M, Mai R, Bierbaum S, Scharnweber D, et al. Evaluation of osseointegration of dental implants coated with collagen, chondroitin sulphate and BMP-4: An animal study. Int J Oral Maxillofac Surg 2008;37:54-9.

57. Thierer T, Davliakos JP, Keith JD, Sanders JJ, Tarnow DP, Rivers JA. Five-year prospective clinical evaluation of highly crystalline HA MP-l-coated dental implants. J Oral Implantol 2008;34:39-46.

58. Graf HL, Stoeva S, Armbruster FP, Neuhaus J, Hilbig H. Effect of bone sialoprotein and collagen coating on cell attachment to TICER and pure titanium implant surfaces. Int J Oral Maxillofac Surg 2008;37:634-40.

59. De Maeztu MA, Braceras I, Alava JI, Gay-Escoda C. Improvement of osseointegration of titanium dental implant surfaces modified with $\mathrm{CO}$ ions: A comparative histomorphometric study in beagle dogs. Int J Oral Maxillofac Surg 2008;37:441-7.

60. Frojd V, Franke-Stenport V, Meirelles L, Wennerberg A. Increased bone contact to a calcium-incorporated oxidized commercially pure titanium implant: An invivo study in rabbits. Int J Oral Maxillofac Surg 2008;37: 561-6.

61. Munisamy S, Vaidyanathan TK, Vaidyanathan J. A bonelike precoating strategy for implants: Collagen immobilization and mineralization on pure titanium implant surface. J Oral Implantol 2008;34:67-75.

62. Sawase T, Jimbo R, Baba K, Shibata Y, Ikeda T, Atsuta M. Photo-induced hydrophilicity enhances initial cell behavior and early bone apposition. Clin Oral Implants Res 2008;19:491-6.

63. Rossi S, Tirri T, Paldan H, Kuntsi-Vaattovaara H, Tulamo R, Narhi T. Peri-implant tissue response to TiO2 surface modified implants. Clin Oral Implants Res 2008;19:348-55.

64. Yang GL, He FM, Yang XF, Wang XX, Zhao SF. Bone responses to titanium implants surface-roughened by sandblasted and double etched treatments in a rabbit model. Oral Surg Oral Med Oral Pathol Oral Radiol Endod 2008;106:516-24.
65. Mangano C, Perrotti V, Iezzi G, Scarano A, Mangano F, Piattelli $A$. Bone response to modified titanium surface implants in nonhuman primates (Papio ursinus) and humans: Histological evaluation. J Oral Implantol 2008;34:17-24.

66. Gurgel BC, Goncalves PF, Pimentel SP, Nociti FH, Sallum EA, Sallum AW, et al. An oxidized implant surface improve bone-to-implant contact in pristine bone and bone defects treated with guided bone regeneration: An experimental study in dogs. J Periodontol 2008;79: 1225-31.

67. Le Guehennec L, Goyenvalle E, Lopez-Heredia MA, Weiss P, Amouriq Y, Layrolle P. Histomorphometric analysis of the osseointegration of four different implant surfaces in the femoral epiphyses of rabbits. Clin Oral Implants Res 2008;19:1103-10.

68. Jung UW, Choi JY, Kim CS, Cho KS, Chai JK, Kim CK, et al. Evaluation of mandibular posterior single implants with two different surfaces: A 5-year comparative study. J Periodontol 2008;79:1857-63.

69. Fandridis J, Papadopoulos T. Surface characterization of three titanium dental implants. Implant Dent 2008; 17:91-9.

70. Asoda S, Arita T, Koshitomae H, Takakuda K. Mechanical attachment of soft fibrous tissues to implants by using mesh structures. Clin Oral Implants Res 2008;19: 11717 .

71. Hoffmann O, Angelov N, Gallez F, Jung RE, Weber FE. The zirconia implant-bone interface: A preliminary histologic evaluation in rabbits. Int J Oral Maxillofac Implants 2008;23:691-5.

72. Langhoff JD, Voelter K, Scharnweber D, Schnabelrauch M, Schlottig F, Hefti T, et al. Comparison of chemically and pharmaceutically modified titanium and zirconia implant surfaces in dentistry: A study in sheep. Int J Oral Maxillofac Surg 2008;37:1 125-32.

73. Nelson K, Semper W, Hildebrand D, Ozyuvaci H. A retrospective analysis of sandblasted, acid-etched implants with reduced healing times with an observation period of up to 5 years. Int J Oral Maxillofac Implants 2008;23:726-32.

74. Bugea C, Luongo R, Di Iorio D, Cocchetto R, Celletti R. Bone contact around osseointegrated implants: Histologic analysis of a dual-acid-etched surface implant in a diabetic patient. Int J Periodontics Restorative Dent 2008;28:145-51.

75. Bornstein MM, Valderrama P, Jones AA,Wilson TG, Seibl $\mathrm{R}$, Cochran DL. Bone apposition around two different sandblasted and acid-etched titanium implant surfaces: A histomorphometric study in canine mandibles. Clin Oral Implants Res 2008;19:233-41. 
76. Oliva J, Oliva X, Oliva JD. Ovoid zirconia implants: Anatomic design for premolar replacement. Int J Periodontics Restorative Dent 2008;28:609-15.

77. Pirker W, Kocher A. Immediate, non-submerged, rootanalogue zirconia implant in single tooth replacement. Int J Oral Maxillofac Surg 2008;37:293-5.

78. Depprich R, Zipprich H, Ommerborn M, Mahn E, Lammers L, Handschel J, et al. Osseointegration of zirconia implants: An SEM observation of the boneimplant interface. Head Face Med 2008;4:25.

79. Kollar A, Huber S, Mericske E, Mericske-Stern R. Zirconia for teeth and implants: A case series. Int J Periodontics Restorative Dent 2008;28:479-87.

80. Wikesjo UM, Xiropaidis AV, Qahash M, Lim WH, Sorensen RG, Rohrer MD, et al. Bone formation at recombinant human bone morphogenetic protein-2-coated titanium implants in the posterior mandible (Type II bone) in dogs. J Clin Periodontol 2008;35:985-91.

81. Wikesjo UM, Qahash M, Polimeni G, Susin C, Shanaman $\mathrm{RH}$, Rohrer MD, et al. Alveolar ridge mentation using implants coated with recombinant human bone morphogenetic protein-2: Histologic observations. J Clin Periodontol 2008;35:1001-10.

82. Nagassa ME, Daw AE, Rowe WG, Carley A, Thomas DW, Moseley R. Optimisation of the hydrogen peroxide pretreatment of titanium: Surface characterisation and protein adsorption. Clin Oral Implants Res 2008;19: 1317-26.

83. Jung RE, Jones AA, Higginbottom FL, Wilson TG, Schoolfield J, Buser D, et al. The influence of nonmatching implant and abutment diameters on radiographic crestal bone levels in dogs. J Periodontol 2008;79:260-70.

84. Degidi M, Piattelli A, Carinci F. Clinical outcome of narrow diameter implants: A retrospective study of 510 implants. J Periodontol 2008;79:49-54.

85. Veltri M, Ferrari M, Balleri P. One-year outcome of narrow diameter blasted implants for rehabilitation of maxillas with knife-edge resorption. Clin Oral Implants Res 2008;19:1069-73.

86. Allum SR, Tomlinson RA, Joshi R. The impact of loads on standard diameter, small diameter and mini implants: A comparative laboratory study. Clin Oral Implants Res 2008; 19:553-9.

87. Quaresma SE, Cury PR, Sendyk WR, Sendyk C. A finite element analysis of two different dental implants: Stress distribution in the prosthesis, abutment, implant, and supporting bone. J Oral Implantol 2008;34:1-6.

88. Schrotenboer J, Tsao YP, Kinariwala V, Wang HL. Effect of microthreads and platform switching on crestal bone stress levels: A finite element analysis. J Periodontol 2008;79:2166-72.

89. Karamanis S, Angelopoulos C, Tsoukalas D, Parissis N. Immediate flapless implant placement and provisionalization: Challenge for optimum esthetics and function: Acase report. J Oral Implantol 2008;34:52-8.

90. Hassan KS, Kassim A, Al Ogaly AU. A comparative evaluation of immediate dental implant with autogenous versus synthetic guided bone regeneration. Oral Surg Oral Med Oral Pathol Oral Radiol Endod 2008;106: e8-15.

91. Ataullah K, Chee LF, Peng LL, Tho CY, Wei WC, Baig MR. Implant placement in extraction sockets: A short review of the literature and presentation of a series of three cases. J Oral Implantol 2008;34:97-106.

92. Buser D, Chen ST, Weber HP, Belser UC. Early implant placement following single-tooth extraction in the esthetic zone: Biologic rationale and surgical procedures. Int J Periodontics Restorative Dent 2008;28:441-51.

93. Fugazzotto PA. Implant placement at the time of maxillary molar extraction: Treatment protocols and report of results. J Periodontol 2008;79:216-23.

94. Fugazzotto PA. Implant placement at the time of mandibular molar extraction: Description of technique and preliminary results of 341 cases. J Periodontol 2008;79:737-47.

95. Guida L, Iezzi G, Annunziata M, Salierno A, Iuorio G, Costigliola G, et al. Immediate placement and loading of dental implants: A human histologic case report. J Periodontol 2008;79:575-81.

96. Degidi M, Novaes AB,Jr, Nardi D, Piattelli A. Outcome analysis of immediately placed, immediately restored implants in the esthetic area: The clinical relevance of different interimplant distances. J Periodontol 2008;79: 1056-61.

97. Susarla SM, Chuang SK, Dodson TB. Delayed versus immediate loading of implants: Survival analysis and risk factors for dental implant failure. J Oral Maxillofac Surg 2008;66:251-5.

98. Donati M, La Scala V, Billi M, Di Dino B, Torrisi P, Berglundh T. Immediate functional loading of implants in single tooth replacement: A prospective clinical multicenter study. Clin Oral Implants Res 2008;19:740-8.

99. Fischer K, Stenberg T, Hedin M, Sennerby L. Five-year results from a randomized, controlled trial on early and delayed loading of implants supporting full-arch prosthesis in the edentulous maxilla. Clin Oral Implants Res 2008;19:433-41.

100. Guncu MB, Aslan Y, Tumer C, Guncu GN, Uysal S. Inpatient comparison of immediate and conventional 
loaded implants in mandibular molar sites within 12 months. Clin Oral Implants Res 2008;19:335-41.

101. Kim SH, Choi BH, Li J, Kim HS, Ko CY, Jeong SM, et al. Peri-implant bone reactions at delayed and immediately loaded implants: An experimental study. Oral Surg Oral Med Oral Pathol Oral Radiol Endod 2008;105:144-8.

102. Boronat A, Penarrocha M, Carrillo C, Marti E. Marginal bone loss in dental implants subjected to early loading (6 to 8 weeks postplacement) with a retrospective shortterm follow-up. J Oral Maxillofac Surg 2008;66:246-50.

103. Huang HL, Hsu JT, Fuh LJ, Tu MG, Ko CC, Shen YW. Bone stress and interfacial sliding analysis of implant designs on an immediately loaded maxillary implant: A non-linear finite element study. J Dent 2008;36:409-17.

104. Galli F, Capelli M, Zuffetti F, Testori T, Esposito M. Immediate non-occlusal vs early loading of dental implants in partially edentulous patients: $A$ multicentre randomized clinical trial. Peri-implant bone and soft-tissue levels. Clin Oral Implants Res 2008; 19:546-52.

105. Ganeles J, Zollner A, Jackowski J, ten Bruggenkate C, Beagle J, Guerra F. Immediate and early loading of Straumann implants with a chemically modified surface (SLActive) in the posterior mandible and maxilla: 1-year results from a prospective multicenter study. Clin Oral Implants Res 2008;19:1119-28.

106. Collaert B, De Bruyn H. Immediate functional loading of Tioblast dental implants in full-arch edentulous maxillae: A 3-year prospective study. Clin Oral Implants Res 2008; 19:1254-60.

107. Allum SR. Immediately loaded full-arch provisional implant restorations using CAD/CAM and guided placement: Maxillary and mandibular case reports. $\mathrm{Br}$ Dent J 2008;204:377-81.

108. Azari A, Nikzad S. Flapless implant surgery: Review of the literature and report of 2 cases with computerguided surgical approach. J Oral Maxillofac Surg 2008;66:1015-21.

109. Cafiero C, Annibali S, Gherlone E, Grassi FR, Gualini F, Magliano A, et al. Immediate transmucosal implant placement in molar extraction sites: A 12-month prospective multicenter cohort study. Clin Oral Implants Res 2008;19:476-82.

110. Choi BH, Li J, Kim HS, Ko CY, Jeong SM, Xuan F. Comparison of submerged and nonsubmerged implants placed without flap reflection in the canine mandible. Oral Surg Oral Med Oral Pathol Oral Radiol Endod 2008;105:561-5.

111. Jeong SM, Choi BH, Li J, Ahn KM, Lee SH, Xuan F. Bone healing around implants following flap and mini-flap surgeries: A radiographic evaluation between stage I and stage II surgery. Oral Surg Oral Med Oral Pathol Oral Radiol Endod 2008;105:293-6.

112. Merli M, Bernardelli F, Esposito M. Immediate versus early nonocclusal loading of dental implants placed with a flapless procedure in partially edentulous patients: Preliminary results from a randomized controlled clinical trial. Int J Periodontics Restorative Dent 2008;28:453-9.

113. Ruppin J, Popovic A, Strauss M, Spuntrup E, Steiner A, Stoll C. Evaluation of the accuracy of three different computer-aided surgery systems in dental implantology: Optical tracking vs stereolithographic splint systems. Clin Oral Implants Res 2008;19:709-16.

114. Bousquet F, Joyard M. Surgical navigation for implant placement using transtomography. Clin Oral Implants Res 2008;19:724-30.

115. Casap N,Wexler A, Eliashar R. Computerized navigation for surgery of the lower jaw: Comparison of 2 navigation systems. J Oral Maxillofac Surg 2008;66:1467-75.

116. Ersoy AE, Turkyilmaz I, Ozan O, McGlumphy EA. Reliability of implant placement with stereolithographic surgical guides generated from computed tomography: Clinical data from 94 implants. J Periodontol 2008;79: $1339-45$

117. Heiland M, Pohlenz P, Blessmann M, Werle H, Fraederich M, Schmelzle R, et al. Navigated implantation after microsurgical bone transfer using intraoperatively acquired cone-beam computed tomography data sets. Int J Oral Maxillofac Surg 2008;37:70-5.

118. Fickl S, Zuhr O, Wachtel H, Bolz W, Huerzeler MB. Hard tissue alterations after socket preservation: An experimental study in the beagle dog. Clin Oral Implants Res 2008;19:1111-8.

119. Cardaropoli D, Cardaropoli G. Preservation of the postextraction alveolar ridge: A clinical and histologic study. Int J Periodontics Restorative Dent 2008;28:469-77.

120. Araujo M, Linder E, Wennstrom J, Lindhe J. The influence of Bio-Oss Collagen on healing of an extraction socket: An experimental study in the dog. Int J Periodontics Restorative Dent 2008;28:123-35.

121. Barone A, Aldini NN, Fini M, Giardino R, Calvo Guirado $\mathrm{JL}$, Covani U. Xenograft versus extraction alone for ridge preservation after tooth removal: A clinical and histomorphometric study. J Periodontol 2008;79: 1370-7.

122. Wang HL, Tsao YP. Histologic evaluation of socket mentation with mineralized human allograft. Int J Periodontics Restorative Dent 2008;28:231-7.

123. Pieri F, Corinaldesi G, Fini M, Aldini NN, Giardino R, Chetti C. Alveolar ridge mentation with titanium mesh and a combination of autogenous bone and anorganic 
bovine bone: A 2-year prospective study. J Periodontol 2008;79:2093-103.

124. Meijndert L, Raghoebar GM, Meijer HJ, Vissink A. Clinical and radiographic characteristics of single-tooth replacements preceded by local ridge mentation: A prospective randomized clinical trial. Clin Oral Implants Res 2008;19:1295-303.

125. Carmagnola D, Abati S, Celestino S, Chiapasco M, Bosshardt D, Lang NP. Oral implants placed in bone defects treated with Bio-Oss, Ostim-Paste or PerioGlas: An experimental study in the rabbit tibiae. Clin Oral Implants Res 2008;19:1246-53.

126. Dhore CR, Snel SJ, Jacques SV, Naert IE, Frank Walboomers X, Jansen JA. In vitro osteogenic potential of bone debris resulting from placement of titanium screw-type implants. Clin Oral Implants Res 2008;19: 606-11.

127. Tezulas E, Dilek O. Contamination of autogenous bone grafts collected from dental implant sites via osteotomy: A review. Oral Surg Oral Med Oral Pathol Oral Radiol Endod 2008; 106:679-84.

128. Gotz W, Gerber T, Michel B, Lossdorfer S, Henkel KO, Heinemann F. Immunohistochemical characterization of nanocrystalline hydroxyapatite silica gel (NanoBone) osteogenesis: A study on biopsies from human jaws. Clin Oral Implants Res 2008;19:1016-26.

129. Mardas N, Stavropoulos A, Karring T. Calvarial bone regeneration by a combination of natural anorganic bovine-derived hydroxyapatite matrix coupled with a synthetic cell-binding peptide (PepGen): An experimental study in rats. Clin Oral Implants Res 2008;19: 1010-15.

130. Tudor C, Srour S, Thorwarth M, Stockmann P, Neukam FW, Nkenke E, et al. Bone regeneration in osseous defects-application of particulated human and bovine materials. Oral Surg Oral Med Oral Pathol Oral Radiol Endod 2008; 105:430-6.

131. De Oliveira RC, De Oliveira FH, Cestari TM, Taga R, Granjeiro JM. Morphometric evaluation of the repair of critical-size defects using demineralized bovine bone and autogenous bone grafts in rat calvaria. Clin Oral Implants Res 2008; 19:749-54.

132. Kalish BP, Schuster GS, Peacock ME, Cuenin MF, Swiec GD, Potter BJ, et al. Influence of matrix-suspended demineralized bone on osseous repair using a criticalsized defect in the rat (Rattus norvegicus) calvarium. J Oral Implantol 2008;34:83-9.

133. Jafarian M, Eslaminejad MB, Khojasteh A, Mashhadi Abbas F, Dehghan MM, Hassanizadeh R, et al. Row- derived mesenchymal stem cells-directed bone regeneration in the dog mandible: $A$ comparison between biphasic calcium phosphate and natural bone mineral. Oral Surg Oral Med Oral Pathol Oral Radiol Endod 2008; 105:e14-24.

134. Schwarz F, Rothamel D, Herten M, Ferrari D, Sager M, Becker J. Lateral ridge mentation using particulated or block bone substitutes biocoated with rhGDF-5 and rhBMP-2: An immunohistochemical study in dogs. Clin Oral Implants Res 2008;19:642-52.

135. Leknes KN, Yang J, Qahash M, Polimeni G, Susin C, Wikesjo UM. Alveolar ridge mentation using implants coated with recombinant human bone morphogenetic protein-2: Radiographic observations. Clin Oral Implants Res 2008;19:1027-33.

136. Intini G, Andreana S, Buhite RJ, Bobek LA. A comparative analysis of bone formation induced by human demineralized freeze-dried bone and enamel matrix derivative in rat calvaria critical-size bone defects. J Periodontol 2008;79:1217-24.

137. Moriyama Y, Ayukawa Y, Ogino Y, Atsuta I, Koyano K. Topical application of statin affects bone healing around implants. Clin Oral Implants Res 2008;19:600-5.

138. Zubery Y, Nir E, Goldlust A. Ossification of a collagen membrane cross-linked by sugar: A human case series. J Periodontol 2008;79:1101-7.

139. Tal H, Kozlovsky A, Artzi Z, Nemcovsky CE, Moses O. Cross-linked and non-cross-linked collagen barrier membranes disintegrate following surgical exposure to the oral environment: A histological study in the cat. Clin Oral Implants Res 2008;19:760-6.

140. Sverzut CE, Faria PE, Magdalena CM, Trivellato AE, Mello-Filho FV, Paccola CA, et al. Reconstruction of mandibular segmental defects using the guided-bone regeneration technique with polylactide membranes and/or autogenous bone graft: A preliminary study on the influence of membrane permeability. J Oral Maxillofac Surg 2008;66:647-56.

\section{CORRESPONDENCIA}

\author{
Dr. Cosme Gay Escoda \\ Centro Médico Teknon \\ Instituto de Investigación Biomédica IDIBELL \\ C/ Vilana, 12 \\ 08022 Barcelona
}

E-mail: cgay@ub.edu

http://www.gayescoda.com 
